\title{
The Effect of Nitrogen Flow Rate on the Loadbearing Capacity from Nano- to Macro-Hardness of Austenitic Stainless Steels Magnetron Sputtering-Coated with Stainless Steel Films
}

\author{
Carlos M. Garzón ${ }^{1 *}$ (D), Giovanny A. Vergara ${ }^{2}$, Abel A. C. Recco ${ }^{3}$ \\ ${ }^{I}$ Universidad Nacional de Colombia - UNal, Departamento de Física, Bogotá D.C., Colombia \\ ${ }^{2}$ Universidad Nacional de Colombia, Departamento de Ingeniería Mecánica y Mecatrónica, Bogotá \\ D.C., Colombia \\ ${ }^{3}$ Universidade do Estado de Santa Catarina - UDESC, Departamento de Física, Joinville, SC, Brasil
}

Received: August 05, 2019; Revised: May 01, 2020; Accepted: May 09, 2020

UNS S31603 stainless steel (SS) substrates were covered by reactive magnetron-sputtering with protective SS coatings of the same steel specification. A mechanical characterization study (through nano-, micro- and macro-hardness tests) of samples obtained under two different sputtering conditions and varying the $\mathrm{N}_{2}$ gas flow rate was carried out. This contribution aimed at appraising the effects of varying the nitrogen flow rate on hardness, elastic modulus, and susceptibility to indentation-induced crack formation of the coated SSs. Nitrogen-free samples displayed body-centered cubic (BCC) films with 9.0-9.4 GPa hardness and 203-206 GPa elastic modulus, while their susceptibility to indentation-induced cracking varied between superior and moderated among the two sets of sputtering conditions studied. Samples alloyed with 4-6 N at-\% displayed a predominantly face-centered cubic (FCC) structure, 9.4 GPa hardness, 196-218 GPa elastic modulus, and superior resistance to crack formation. Samples with 11.5-22.0 N at-\% were fully composed of the FCC structure, displayed 12.4-15.2 GPa hardness, 188-193 GPa elastic modulus, and moderated resistance to indentation-induced crack formation. Samples with $47.0 \mathrm{~N}$ at- $\%$ displayed FCC compound nitride structure, for which hardness and elastic modulus were $8.1 \mathrm{GPa}$ and $139 \mathrm{GPa}$, respectively. These samples displayed low resistance to crack formation.

Keywords: stainless steels, S-phase, loadbearing capacity, steel films, composite hardness, fragile failure.

\section{Introduction}

Austenitic stainless steels (ASSs) are commonly used as anticorrosive structural alloys ${ }^{1}$. Li et al. ${ }^{2}$ showed superior anticorrosion properties of stainless steel (SS) films fabricated by magnetron-sputtering. Li et al. ${ }^{2}$ showed that SS-sputtered films exhibit higher protection against corrosion than similar volumetric conventional $\mathrm{SSs}^{3}$. It was attributed to improved stability of the passive layer of SS coatings against electrolyte attack ${ }^{3}$.

In conventional structures, ASSs exhibit a ductile character. However, they lack scratch resistance and hardness. Lo et al. ${ }^{1}$ reviewed the diverse processes developed for surface modification of ASSs, with the aim of improving their antiscratching capacity and hardness. In particular, this article deals with the surface modification of UNS S31603 stainless steel (SS) by covering conventional steel samples with SS protective films using magnetron-sputtering.

Magnetron-sputtering allows the covering of diverse substrate materials with protective superficial layers of different SS specifications ${ }^{2-18}$. Films with thicknesses in the order of magnitude of $1.0 \mu \mathrm{m}$ can be obtained straightforwardly on either heated or unheated substrates or as interlayers ${ }^{2-18}$.

*e-mail: cmgarzono@unal.edu.co.
Zhang et al. ${ }^{4}$ reported on the phase stability of SS films as a function of both target chemical composition and external substrate heating.

The increased use of SS films in diverse technological areas has been driven by their magnetic properties ${ }^{5,6}$, electrical properties $^{7,8}$, corrosion resistance ${ }^{2,3,9}$, biocompatibility performance ${ }^{10}$, and surface reflective properties ${ }^{11-13}$. AldrichSmith et al..$^{19}$ compared the antiwear performance of SS films with typical $\mathrm{CrN}$ tribological films, and saw that sputtered SS films are neither intrinsically anti-scratch nor antiwear materials. However, at different structural applications, moderate capacity of bearing contact loads is essential for avoiding in-service film degradation. Therefore, SS film hardness and tribological performance have been studied ${ }^{20-22}$.

$\mathrm{N}$-bearing SS films have been developed to further improve the hardness of SS films ${ }^{20,21,23}$. N-bearing films have been obtained by using gas mixtures comprised of $\mathrm{Ar}+\mathrm{N}_{2}$ as sputtering atmosphere s $^{20,21,23}$. In particular, S-phase films (i.e., nitrogen alloyed austenitic films ${ }^{19}$ ) were targeted because of their superior wear resistance ${ }^{21}$.

Von Stebut et al. ${ }^{24}$ reported on ASS films sputtered onto 316L substrates, which exhibited perfect adherent character. Rezakhanlou et al. ${ }^{25}$ reported the perfect adherence 
of films sputtered from $310 \mathrm{SS}$ targets onto structural steels. They studied both C-lean and C-alloyed films. However, other works pointed out impaired susceptibility to film cracking and delamination of SS films when exposed to contact loads ${ }^{26-28}$. Talea et al. ${ }^{26}$ and Colin et al. ${ }^{27}$ reported debonding induced by compressive loads in 304L stainless steel films deposited onto polycarbonate substrates. Eymery and Boubeker studied film-to-substrate adherence for SS films sputtered from 304L targets onto a wide variety of substrates $^{28}$, pointing out impaired film capacity to bear contact and scratch loads ${ }^{28}$ and emphasizing the role of high compressive stresses observed in the films on the impaired film adherence ${ }^{28}$. There is no systematic work appraising the effect of either film structure or film nitrogen content on susceptibility to crack formation under contact loads. This article shows that the resistance to crack formation, and subsequent film delamination, in indentation tests of SS films is meaningfully influenced for variations in the flux of $\mathrm{N}_{2}$ gas in the sputtering atmosphere, which explains, to some extent, the apparently contradictory reports about either outstanding or impaired film capacity to bear contact loads. Further research is needed to stablish the fundamentals of the very dissimilar mechanical performance of SS films onto compliant substrates.

In general terms, endurance of hard films deposited onto compliant substrates is improved when the film's hardness is increased. The $\mathrm{H} / \mathrm{E}$ ratio (hardness to elastic modulus) is commonly associated with film performance under scratch or wear constraints. The effects of overall film nitrogen content on mechanical properties of SS sputtered films needs further study to stablish a relationship between sputtering conditions, film's nitrogen content, film's phases and film's mechanical properties. However, in many systems comprised of a hard film onto a compliant substrate, in-service premature damage could take place due to crack formation and propagation either inside the film or in the film-to-substrate interface. This crack formation strongly depends on the extent of deformation triggered by the contact load, as well as on the film-to-substrate variation of mechanical properties. The effects of variations in SS film structure and nitrogen content on the contact-induced fracture susceptibility of films sputtered onto SS substrates need further studying, aiming to stablish adequate production conditions for obtaining endurable SS films onto compliant SS substrates.

This study aims to assess the influence of variations in the nitrogen flow rate on hardness, elastic modulus,

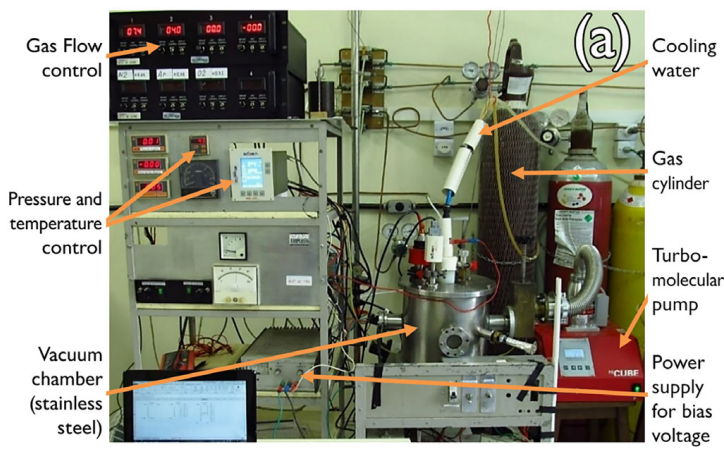

and susceptibility to indentation-induced cracking of UNS S31603 SS substrates coated (by magnetron-sputtering) with SS films of the same material specification. Two sets of samples, obtained at different typical operational conditions of the sputtering reactor, are studied (one part of the samples was prepared without external substrate heating, non-bias voltage, and $7 \mathrm{Wcm}^{-2}$ power density, while the other part was processed at power density $10.3 \mathrm{Wcm}^{-2},-250 \mathrm{~V}$ bias voltage, and external substrate heating at $573 \mathrm{~K}$ ). The paper presents the results of mechanical characterization by depthsensing nano-indentation, conventional micro-indentation, and conventional macro-indentation experiments. From this, the intrinsic hardness and elastic modulus of the films, filmsubstrate composite hardness, resistance to crack formation under indentation loads and related damage mechanisms were assessed.

\section{Experimental}

Test samples of the steel UNS S31603 were covered by magnetron sputtering with stainless steel films obtained using a target of the same steel specification (namely, UNS S31603). Test samples were $2 \mathrm{~mm}$-thick cylinders cut from a commercial hot-worked bar $19 \mathrm{~mm}$ in diameter.

The target was obtained by cutting a $101.6 \mathrm{~mm}$-diameter cylinder from a commercial $6.3 \mathrm{~mm}$-thick hot-worked plate. The SS target was placed over a copper holder cooled by water flow.

The chemical composition of both target and substrate were virtually the same; namely, (at-\%) $18.0 \mathrm{Cr}, 9.1 \mathrm{Ni}$, 1.8Mn, 0.8Si, 1.2Mo, 0.14C, and 69.0 Fe.

The substrate samples were initially ground in emery paper, increasing the mesh number up to 1200 , and finally polished in diamond paste slurry, with the final stage in slurries with $3 \mu \mathrm{m}$ average particle size. RMS roughness parameter of polished samples was around $10 \mathrm{~nm}$ (as assessed by atomic force microscopy). Polished samples were cleaned ultrasonically in an acetone bath for around $0.9 \mathrm{ks}$ (15 minutes) and were then washed sequentially in water and isopropyl alcohol, and finally dried in hot air.

The cleaned samples were charged into the deposition chamber, which was comprised of an SS deposition chamber. Figure 1 shows a photography of the home-made sputtering facility (inset a) as well as a schematic representation of the experimental set-up (inset b). Samples were placed at $60 \mathrm{~mm}$ from the target, and then the chamber was closed and evacuated up to $1 \times 10^{-3} \mathrm{~Pa}$ using both mechanical and

Figure 1. (a) Photography and (b) scheme of the experimental set-up for film deposition.

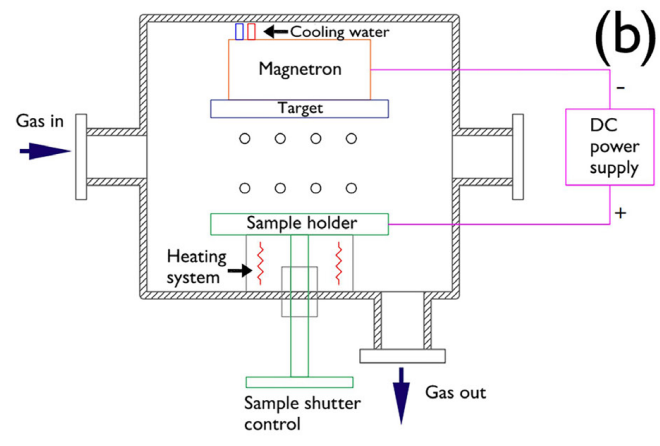


turbo-molecular pumps. The equipment was implemented with a gas mixer, gas flux controller, and pressure controller. One part of the deposition treatments was carried out without substrate heating, while the other part was carried out heating the substrates at $573 \mathrm{~K}$. Samples were heated by radiation lamps. Next, a flux of $1.2 \mathrm{sccm}$ Ar gas was established in the deposition chamber, controlling the absolute pressure to around $0.4 \mathrm{~Pa}$. In several deposition experiments, an additional $\mathrm{N}_{2}$ gas flux was established. Deposition experiments were carried out at varying $\mathrm{N}_{2}$-gas flow rates: namely, 0.0 , $0.53,1.82$, and $11.3 \mathrm{sccm}$. The final chamber pressure was dependent on the actual $\mathrm{N}_{2}$ flow rate used. The final chamber absolute pressure was assessed with a capacitive pressure gauge and was between around 0.4 and $1.9 \mathrm{~Pa}$.

The reactive deposition hysteresis curve (not shown) was analyzed, and it was observed that the SS target became poisoned when the $\mathrm{N}_{2}$ flow rate was higher than around $2.8 \mathrm{sccm}$.

In experiments without external substrate heating, a moderate increasing of sample temperature was observed, which was proportional to elapsed deposition time. It was attributed to both flux of energy from the plasma and condensation heat of absorbed atoms. The maximum surface temperature registered was $320 \mathrm{~K}$. Instead, in experiments with external substrate heating, sample temperature was quite stable, varying $\pm 2 \mathrm{~K}$ around the nominal temperature, namely $573 \mathrm{~K}$.

The aim of this research was not to study the effects of individual variations of temperature nor substrate bias on film's mechanical properties. Instead, this research aimed at studying the effects of changes in the $\mathrm{N}_{2}$ gas flow rate on film's mechanical properties at two very different operational conditions of the sputtering reactor.

The effect of $\mathrm{N}_{2}$-gas flow rate (namely, 0.0, 0.53, 1.82, and $11.3 \mathrm{sccm}$ ) on film's load-bearing capacity was studied for samples obtained under two quite different operational conditions of the sputtering reactor. Those two sputtering conditions were selected aiming at (a priori) very different film growth modes. Here we called those group of samples as set-A and set-B.

One set of samples (set-A) was prepared without external substrate heating, non-bias voltage, and $7 \mathrm{Wcm}^{-2}$ power density. The other set of samples (set-B) was processed at power density $10.3 \mathrm{Wcm}^{-2}$, $-250 \mathrm{~V}$ bias voltage, and external substrate heating at $573 \mathrm{~K}$. A DC power supply was used. No individual variations of target applied power, external substrate heating, or bias voltage were carried out.

The total deposition time was varied, from $1.2 \mathrm{ks}$ (experiments with non- $\mathrm{N}_{2}$ flux) up to $2.7 \mathrm{ks}$ (experiments with $11.2 \mathrm{sccm} \mathrm{N}_{2}$ flow rate), aiming to obtain films with similar thicknesses. However, film thickness actually varied; it was between around 3 and $5 \mu \mathrm{m}$.

XRD experiments consisted of conventional scans in the Bragg-Brentano geometry with monochromatic $\mathrm{Cu}$ K- $\alpha$ radiation $(\lambda=1.54056 \AA)$. A conventional diffractometer, Philips PW 1710, was used.

Metallic fraction chemical composition was assessed by EDS analysis in a Tescan Vega 3 scanning electron microscope (SEM) facility. The nitrogen content was appraised by WDS analysis in a JEOL JSM 5900LV SEM facility.

Surface film topography was assessed by scanning 3 $\mu \mathrm{m} \times 3 \mu \mathrm{m}$ areas in an atomic force microscope (AFM)
NanoSurface Nanite-B. Non-contact mode scans were carried out. Both $\mathrm{x}$-axis and $\mathrm{y}$-axis scans were identical. AFM typical resolution was around $0.01 \mathrm{~nm}$ in the vertical direction (z-axis).

In selected samples, a step between a coated and a noncoated region was created by partially covering the sample surface. The height difference between those covered and uncovered areas was assessed with a Vecco, Dektak 150 stylus profiler, and the coating thickness was appraised as such height difference.

Samples were indented on top of film surfaces by either: (i) depth-sensing indentation tests with a Berkovich tip, (ii) conventional microhardness tests with either Knoop or Vickers tips, or (iii) conventional macrohardness tests with either Vickers or Rockwell-C tips. From depth-sensing indentation tests, film intrinsic hardness, film intrinsic elastic modulus, and film-substrate composite hardness were assessed. From the Knoop and Vickers tests, susceptibility to crack formation under indentation loads was assessed. From the Rockwell tests, the overall technological performance of films against delamination and propagation of brittle fracture, under macroscopy plastic deformation of the film-substrate pair, was assessed.

Depth-sensing indentation tests were carried out using a CETR-UMT-02, nanohardness tester. Hardness was assessed by analyzing the force-depth data ( $p$ vs $h$ ), according to the approach developed by Oliver and Pharr $^{29}$. Detection accuracy of the initial tip-substrate contact coordinate was around $2 \mathrm{~nm}$. Both area function of the indenter tip and finite compliance of the load frame were appraised by carrying out a calibration procedure with a commercially available fused silica reference sample, which was delivered with a certified plane strain modulus ( $\mathrm{E}=72 \mathrm{GPa})$. The Poisson's ratios used were 0.29 and 0.17 for steel and fused silica, respectively. Each test point reported is the statistical outcome of either 16 or 32 measurements per sample: the larger the observed dispersion of data, the higher the number of measurements. Two different indentation experiments were carried out, as described next.

Film intrinsic hardness and elastic modulus were assessed by carrying out an indentation test comprised of one loading cycle up to $5.0 \mathrm{mN}$ and subsequent unloading. The whole indentation cycle was comprised of: $15 \mathrm{~s}$ loading stage, $10 \mathrm{~s}$ creep stage, $15 \mathrm{~s}$ unloading stage up to $0.5 \mathrm{mN}, 45 \mathrm{~s}$ drift period, and final unloading stage.

Composite hardness was assessed by cyclical indentation tests at progressive maximum loads. Each cyclical indentation was comprised of eight loading-unloading cycles at the same sample position, carried out with maximum charge per cycle from 5 to $245 \mathrm{mN}$. Each of those loading-unloading cycles consisted of: $15 \mathrm{~s}$ loading up to cycle maximum load, $10 \mathrm{~s}$ creep period, and $15 \mathrm{~s}$ unloading up to $10 \%$ of cycle maximum load. A $45 \mathrm{~s}$ drift period was carried out after the eighth unloading cycle.

Drift correction of nano-indentation data was carried out.

Microhardness tests were carried out in a conventional Leco M-400-G2 tester. Loading time was $30 \mathrm{~s}$, time at maximum load was $30 \mathrm{~s}$, and unloading time was not controlled (unloading time was adjusted internally by a damping mechanism on the appliance that did not allow external controlling). Maximum indentation loads were between 0.025 and $2.0 \mathrm{kgf}$. Four indentations per sample 
were carried out. By examining the worn surfaces in a SEM facility, the susceptibility to crack formation under indentation was appraised. The critical load for triggering crack formation was evaluated.

Macrohardness tests were carried out in a conventional Amsler GMBH tester. Vickers tests with either 3 or $10 \mathrm{kgf}$ maximum load were carried out. Rockwell tests with $150 \mathrm{kgf}$ maximum indentation load were carried out.

Vidakis et al. ${ }^{30}$ described a procedure for evaluating qualitatively the overall resistance to indentation-induced damage of the film-substrate pair from Rockwell-C tests, according to the VDI 3198-recommended procedure. In this article, worn surfaces were evaluated in the SEM according to the approach from Vidakis et al..$^{30}$ and it was assigned a performance index, from HF1 to HF6, where HF1 to HF4 indexes are related to good-enough film performance, whereas HF5 and HF6 indexes are an indication of poor film performance. Such ranking indexes were assessed by comparing the appearance of damage at worn surfaces with a series of standardized damage patterns, presented in Figure 1 in the paper of Vidakis et al. ${ }^{30}$.

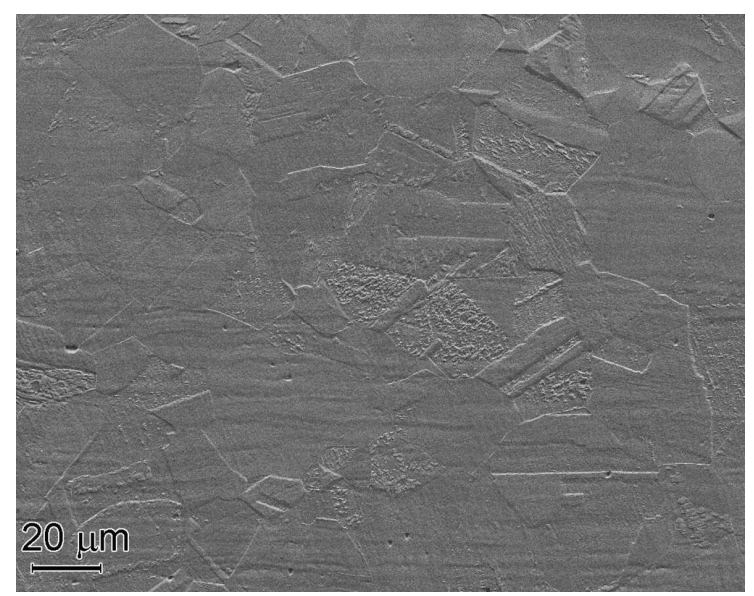

Figure 2. Scanning electron micrograph of the uncovered substrate. Secondary electrons.
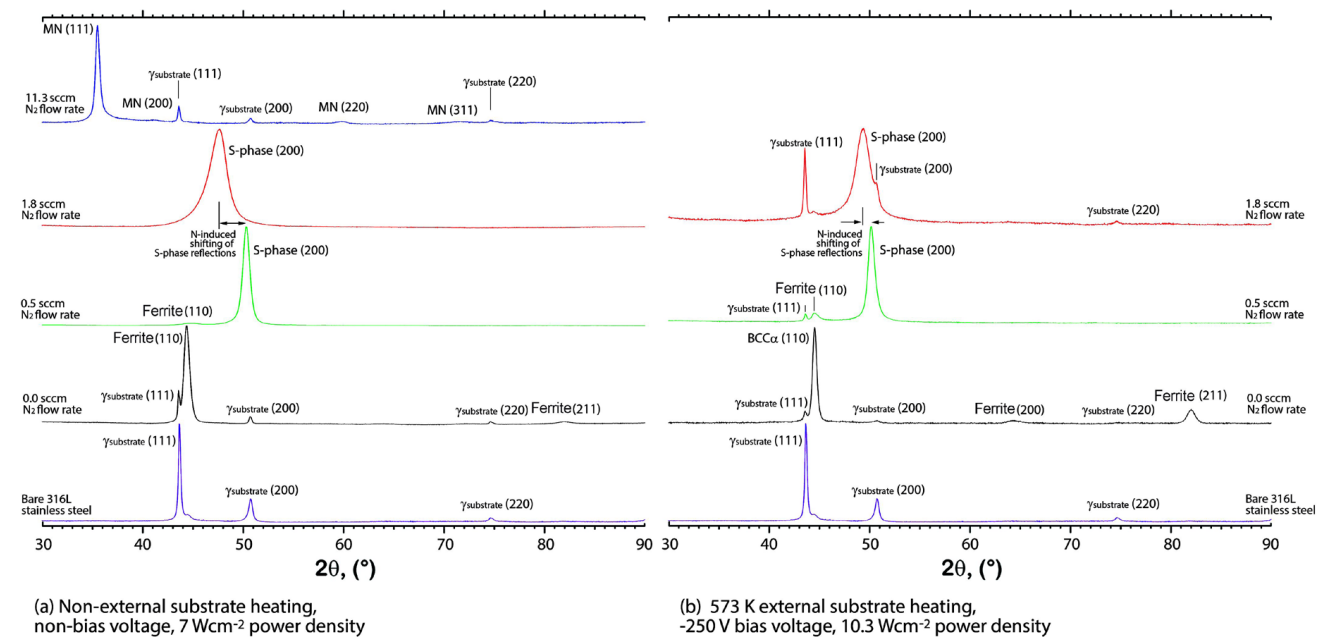

Figure 3. Effects of sputtering conditions on the XRD patterns.

\section{Results}

Figure 2 shows an SEM micrograph of the uncovered substrate. The typical grain structure of an austenitic SS can be seen, with average grain size around $30 \mu \mathrm{m}$.

Figure 3 shows the diffraction patterns obtained. Raw data are presented; i.e., no data-cleaning nor data-fitting procedures were carried out. It can be seen in Figure 3 that in some $\mathrm{X}$-ray diffractograms only a few strong film reflections can be identified. The prevalence of a few of the XRD reflections over the others in SS sputtered films has been discussed elsewhere by Schneider et al. ${ }^{31}$, who explained this as a consequence of film growth with a strong crystallographic texture.

At zero $\mathrm{N}_{2}$ flow rates, the film reflections observed in the XRD scans (Figure 3) are consistent with (110), (200) and (211) reflections arising from body-centered cubic (BCC) structure, space group $1 \mathrm{~m}-3 \mathrm{~m}$, space group number 229, with lattice constant $2.880 \pm 0.005 \AA$. The common name of this phase component is ferrite.

Reflections observed in the XRD scans (Figure 3) of nitrogen-bearing samples were indexed using the face-centered cubic (FCC) structure, space group Fm-3m, space group number 225, with lattice constant varying between $3.624 \pm 0.005 \AA$ and $4.372 \pm 0.005 \AA$, where the higher the nitrogen content the higher the lattice parameter. In nitrogen alloyed samples (excepting those obtained under $11.3 \mathrm{sccm} \mathrm{N}$ flow rate) the XRD film reflections can be indexed as (200) reflection arising from the S-phase, according to reports presented for N-bearing $\mathrm{SS}$ films ${ }^{20,23,31-33}$. In the set-A of samples, as the $\mathrm{N}_{2}$ flow rate was increased from 0.5 to $1.8 \mathrm{sccm}$, the interplanar spacing for (200) reflections increased, from 1.812 $\pm 0.002 \AA$ (a $3.63 \AA$ ) to $1.907 \pm 0.002 \AA$ ( $\mathrm{a} \sim 4.08 \AA)$. The increased lattice constant of S-phase, regarding N-lean austenite $(\mathrm{a} \sim 3.62 \AA)$, is the reason for labeling that phase as expanded austenite ${ }^{32}$.

In the set-B of samples, at $0.53 \mathrm{sccm} \mathrm{N}_{2}$ flow rate, the $\mathrm{XRD}$ scans are in accordance with the simultaneous presence of both the BCC and FCC phases, which were identified with samples already analyzed in this report. No report on literature was prepared on "duplex" stainless steel structures for nanostructured films obtained by magnetron sputtering. 
That duplex stainless steel structures are widely used in technological applications in bulk conventional stainless steels.

Samples in set-A, obtained under $11.3 \mathrm{sccm} \mathrm{N}_{2}$ flow rate, are composed of a phase with an Fm-3m space group lattice and a lattice constant of $4.372 \pm 0.005 \AA$. Such phase is in accordance with the MN compound reported in SS films obtained under sputtering gases that were very rich in $\mathrm{N}_{2}{ }^{33}$. A straightforward characterization of this $\mathrm{MN}$ phase was possible in this contribution, due to the several reflections that are present in the XRD diffractogram (Figure 3, inset $11.3 \mathrm{sccm} \mathrm{N}_{2}$ ), namely (111), (200), (220), and (311).

Table 1 presents phase fractions, average N-content, film hardness, and film elastic modulus for the samples studied. Hardness and elastic modulus in Table 1 were assessed using depth-sensing indentation tests with $5 \mathrm{mN}$ maximum load.

In Figure 3, S-phase reflections are observed at diverse Bragg angles, where a reflection shift to lower diffraction angles can be seen when the N-content in the film is increased. This $\mathrm{N}$-induced shifting of S-phase reflections has been related to increasing of the lattice constant because of nitrogen absorption in the lattice of the FCC crystal structure $^{32}$. The more intense shifting of the S-phase reflections in set-A of samples regarding the set- $\mathrm{B}$, as the $\mathrm{N}_{2}$ flow rate is increased from $0.5 \mathrm{sccm}$ to $1.8 \mathrm{sccm}$, is in accordance with the more pronounced increase of nitrogen content in the set-A of samples, and the associated more pronounced increase of hardness (Table 1).

Samples obtained display very diverse phase structures and nitrogen contents (Figure 3 and Table 1). Ferritic structures are stable when full Ar sputtering atmospheres are used, whereas ferrite destabilization and concomitant austenite stabilization are promoted when $\mathrm{N}_{2}$ is added to the sputtering gas. A direct correlation between the nitrogen in the gas atmosphere and its content in the films was observed, leading to stabilization of the austenite regarding the ferrite as the $\mathrm{N}_{2}$ flow rate was increased. That stabilization of austenite by $\mathrm{N}$-alloying was reported by Bourjot et al. ${ }^{23}$.

No detectable differences were observed between the target and film metallic fraction chemical composition (i.e., no taking into account the nitrogen content). Terwagne et al..$^{34}$ explained this as a straightforward consequence of both the similar sputtering yield of $\mathrm{Fe}, \mathrm{Cr}$, and $\mathrm{Ni}$ and the sputter yield amplification effect. 'The differences in partial sputtering yield for nickel, chromium and iron are very small (1.0, 1.1 and 1.0, respectively, for $500 \mathrm{eV}$ Ar ions) ${ }^{23}$.

Figure 4 shows the on-top surface appearance of sputtered steel films, as observed in the AFM facility. The remarkable flat character of ferrite and S-phase films should be emphasized. In contrast, films comprised of MN nitride display a rougher surface. This is consistent with the broader XRD reflections (Figure 3) for both ferrite and S-phase with regard to the
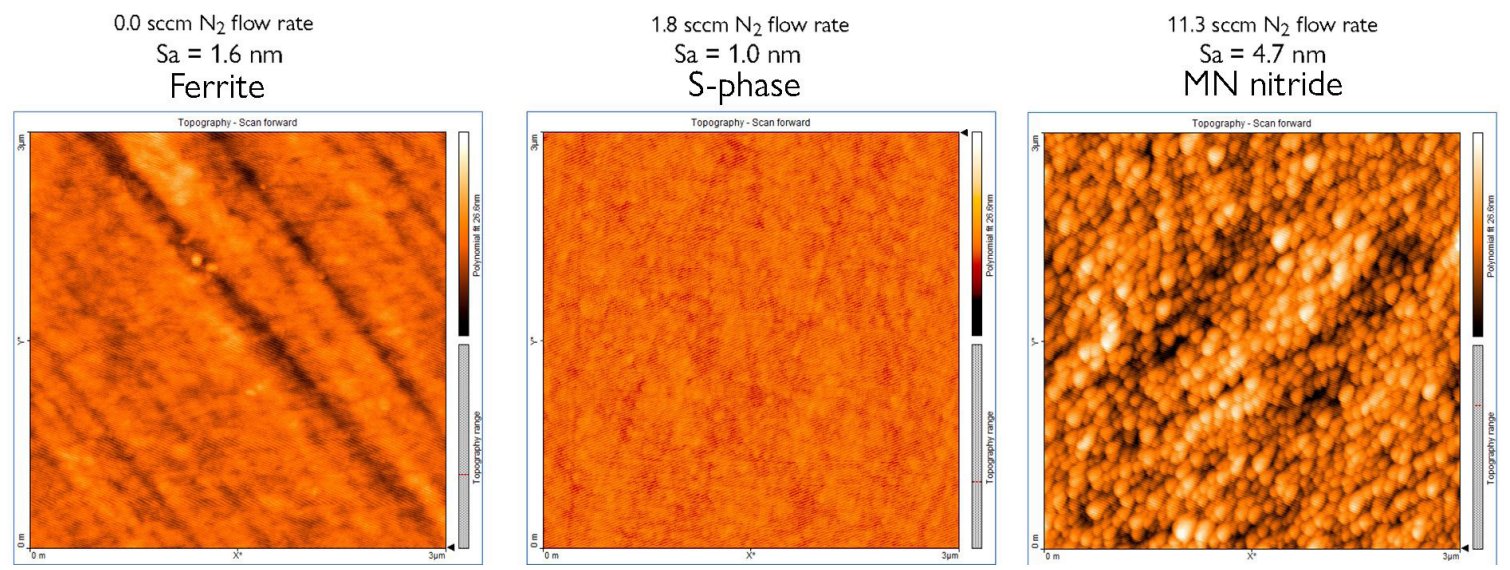

Figure 4. Sample surface appearance, as observed in the AFM facility for films with different phases.

Table 1. Effects of sputtering conditions on XRD-accessed phase fractions, WDS-accessed average N-content, film hardness, and film elastic modulus.

\begin{tabular}{|c|c|c|c|c|c|c|c|}
\hline \multirow{2}{*}{ Sputtering conditions } & \multirow{2}{*}{$\begin{array}{c}\mathrm{N}_{2} \text { flow rate, } \\
\text { sccm }\end{array}$} & \multicolumn{3}{|c|}{ Phase fraction dimensionless } & \multirow{2}{*}{$\begin{array}{c}\text { Average } \\
\text { N-content, } \\
\text { at- } \%\end{array}$} & \multirow{2}{*}{ Hardness GPa } & \multirow{2}{*}{$\begin{array}{c}\text { Elastic } \\
\text { modulus GPa }\end{array}$} \\
\hline & & Ferrite & S-phase* & MN nitride ${ }^{\S}$ & & & \\
\hline \multirow{4}{*}{$\begin{array}{l}\text { Non-substrate } \\
\text { heating, non-bias, } \\
7 \mathrm{Wcm}^{-2}\end{array}$} & 0 & 1.0 & 0.0 & 0.0 & 0 & $9.4^{ \pm 0.5}$ & $206^{ \pm 16}$ \\
\hline & $0.53^{ \pm 0.03}$ & $0.05^{ \pm 0.02}$ & $0.95^{ \pm 0.02}$ & 0.0 & $6.0^{ \pm 2.0}$ & $9.4^{ \pm 0.5}$ & $196^{ \pm 17}$ \\
\hline & $1.82^{ \pm 0.04}$ & 0.0 & 1.0 & 0.0 & $22.0^{ \pm 4.0}$ & $15.2^{ \pm 0.7}$ & $193^{ \pm 8}$ \\
\hline & $11.3^{ \pm 0.05}$ & 0.0 & 0.0 & 1.0 & $47.0^{ \pm 6.0}$ & $8.1^{ \pm 0.6}$ & $139^{ \pm 10}$ \\
\hline \multirow{3}{*}{$\begin{array}{l}573 \mathrm{~K} \text { substrate } \\
\text { heating, }-250 \mathrm{~V} \text { bias, } \\
10.3 \mathrm{Wcm}^{-2}\end{array}$} & 0 & 1.0 & 0.0 & 0.0 & 0 & $9.0^{ \pm 0.5}$ & $203^{ \pm 17}$ \\
\hline & $0.53^{ \pm 0.03}$ & $0.07^{ \pm 0.02}$ & $0.93^{ \pm 0.02}$ & 0.0 & $4.0^{ \pm 2.0}$ & $9.4^{ \pm 0.6}$ & $218^{ \pm 20}$ \\
\hline & $1.82^{ \pm 0.04}$ & 0.0 & 1.0 & 0.0 & $11.5^{ \pm 3.0}$ & $12.4^{ \pm 0.9}$ & $188^{ \pm 13}$ \\
\hline
\end{tabular}

* S-phase is a FCC crystal structure with expanded lattice constant, with regard to nitrogen-lean austenite, due to nitrogen dissolution. ${ }^{\S} \mathrm{MN}$ nitride is a compound phase with FCC crystal structure. Distinction between S-phase and MN nitride was made in accordance with Kappaganthu and Sun ${ }^{33}$. XRD scans are presented in Figure 2. 
$\mathrm{MN}$ nitride, which displayed narrow XRD reflections (wide XRD reflections are commonly related to small crystallites, while narrow reflections are related to coarse crystallites).

No meaningful differences in XRD scan profiles (Figure 3 ) or in mechanical properties (Table 1) were detected in samples obtained under full Ar-gas sputtering atmospheres among set-A and set-B. According to Thornton, changes in the growth mode between those two sets of samples are expected ${ }^{35}$. The absence of substrate heating and lower target-applied power in samples of set-A could be associated with decreased adatom energy ${ }^{36,37}$. However, such expected changes in film structure, and concomitant changes in mechanical properties, were undetected by either XRD analysis or depth-sensing indentation tests.

Samples with mild nitrogen additions (4 and $6 \mathrm{~N}$ at-\%) exhibited negligible changes in hardness $(9.4 \mathrm{GPa})$ and moderate variations of film elastic modulus (196 and $218 \mathrm{GPa}$ ), when compared with N-lean samples.

Moderate nitrogen additions (11.5 and $22 \mathrm{~N}$ at- $\%$ ) induced a significant increase in hardness (12.4 and $15.2 \mathrm{GPa})$ and a minor decrease in elastic modulus (188 and $193 \mathrm{GPa}$ ).

Intense nitrogen additions (47 $\mathrm{N}$ at-\%) led to softer structures $(8.1 \mathrm{GPa})$ with steeply reduced elastic modulus (139 GPa).

Figure 5 shows the dependence of hardness on indentation depth for depth-sensing indentation tests of covered samples as well as for the two reference samples: namely, fused silica and uncovered SS. Raw data are shown. The uncovered SS sample was previously polished in colloidal silica to reduce surface work-hardening.

In systems comprised of a compliant substrate and a hard film, it a decrease of hardness is expected when the indentation
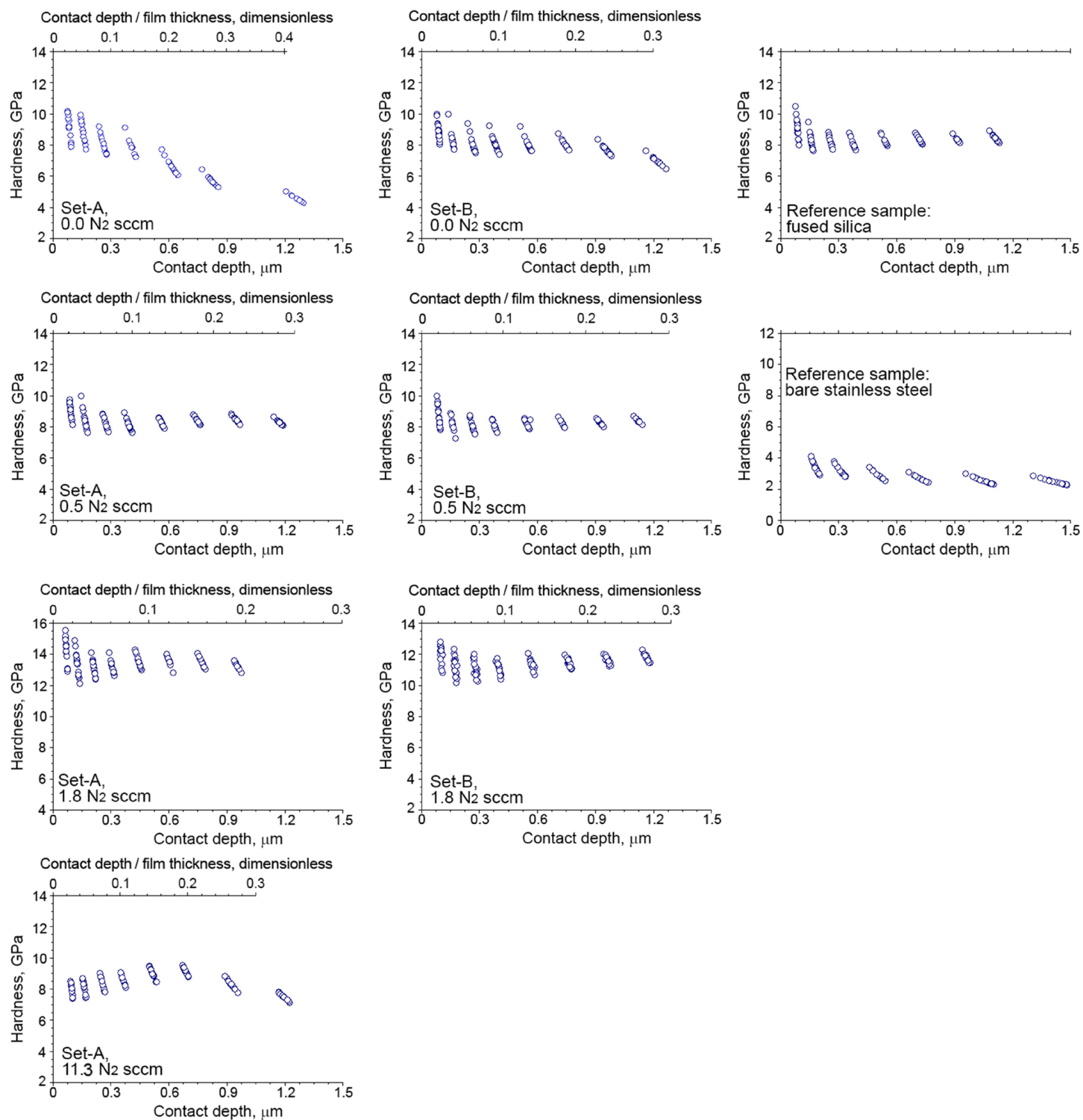

Figure 5. Effects of sputtering conditions on the relationship between hardness and indentation depth. Set-A: non-substrate heating, non-bias, $7 \mathrm{Wcm}^{-2}$; Set-B: $573 \mathrm{~K}$ substrate heating, -250 V bias, $10.3 \mathrm{Wcm}^{-2}$. Results from on-top depth-sensing hardness with cyclical indentations at progressive maximum loads are reported. Maximum load varied from 5 to $245 \mathrm{mN}$. Berkovich tip. 
depth is higher than around 0.07-0.1 film thickness (e.g., references Sakharova et al..$^{38}$ and Puchi-Cabrera et al. $\left.{ }^{39}\right)$. These changes are triggered by the transition of elastic-plastic properties, from intrinsic film properties (lower indentation depths) to composite film-substrate properties (higher indentation depths). That is in accordance with throughthickness hardness (Figure 5) for films obtained without nitrogen additions, however a deviation from that classical hardness-depth relationship is observed for $\mathrm{N}$-alloyed samples. In samples gently alloyed with nitrogen (4 and $6 \mathrm{~N}$ at-\%), an almost flat through-thickness hardness can be seen at both film intrinsic region and the early film-to-substrate composite region. In samples with higher nitrogen additions $(11.5,22.0$ and $47.0 \mathrm{~N}$ at-\%), an anisotropic throughthickness hardness profile can be seen. On those samples, no significant decrease of the composite hardness with regard to near surface film hardness could be seen for indentation depths as high as $0.2-0.25$ film thickness. Such anisotropy in through-thickness film hardness can be associated with the formation of harder structures near the film-substrate interface, triggered by nitrogen additions. This could be related to: (i) anisotropic residual stress distribution inside the film (e.g., reference Liu et al. ${ }^{40}$ ); (ii) changes in the film growth mode from earlier growth stages up to later stages (e.g., references Thornton ${ }^{35}$ and Kappaganthu and Sun ${ }^{41}$ ); or (iii) unreported nitrogen hardening of the substrate near the film-substrate interface. Eventual heterogeneities in nitrogen profiles were not contemplated, because homogeneity of nitrogen distribution inside the films has been reported ${ }^{17}$.

Figure 6 shows the surface appearance of selected samples studied by Knoop and Vickers indentation, as observed in the SEM facility. Figure 7 shows the surface appearance of covered samples tested under Rockwell indentation, as observed in the SEM facility. Table 2 presents: (i) the critical loads for inducing formation of cracks under Knoop and Vickers indentations; and (ii) the HF performance index for samples tested under Rockwell indentations (VDI 3198-recommended procedure $^{30}$ ).
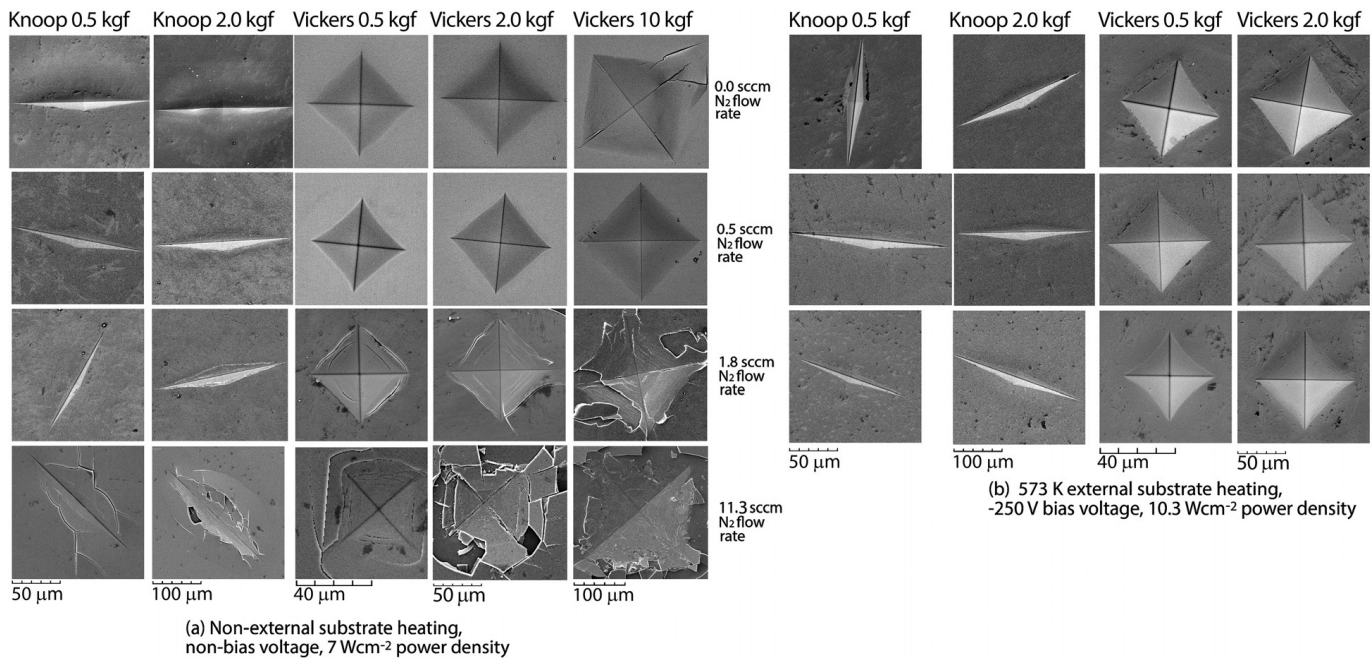

(b) 573 Kexternal substrate heating $-250 \mathrm{~V}$ bias voltage, $10.3 \mathrm{Wcm}^{-2}$ power density excessively alloyed with nitrogen. HF index dropped from HF1-HF2 to HF6 as the $\mathrm{N}_{2}$ flow rate varied from 0.0 up to $11.3 \mathrm{sccm}$. The HF index also showed a poorer performance of samples in set-A than in set-B, obtained with $0.0 \mathrm{sccm}$ $\mathrm{N}_{2}$ flow rate. The outstanding performance of some samples should be emphasized (set-A: $0.53 \mathrm{sccm} \mathrm{N}$ flow rate set-B: 0.0 and $0.53 \mathrm{sccm} \mathrm{N}_{2}$ flow rate): no formation of cracks was detected on them either at the imprint borders or inside the imprints after high magnification SEM observations (not shown).

The Knoop and Vickers indentation tests showed increased susceptibility to crack formation in films alloyed with either 22 or $48 \mathrm{~N}$ at-\%. Mild susceptibility to crack formation in films obtained with $0.0 \mathrm{sccm} \mathrm{N}_{2}$ flow rate in set-A of samples and $1.8 \mathrm{sccm} \mathrm{N}_{2}$ flow rate in set-B was also shown. Other samples displayed a fully ductile deformation character for indentation loads as high as $10 \mathrm{kgf}$.

\section{Analysis and Discussion}

Prevalence of ferrite in nitrogen-lean structures and stabilization of the austenite in nitrogen-bearing structures (so-called S-phase) was observed in this contribution. Similar results were reported for SS films sputtered from 303, 304L, 316 , and $316 \mathrm{~L}$ targets ${ }^{10,24,32-34,41}$. No detectable differences between target and film chemical composition were observed in this contribution and elsewhere ${ }^{34}$. The prevalence of the assumed 'less stable' ferrite instead of the assumed 'more stable' austenite triggered diverse interpretations. This stability hierarchy between ferrite and austenite is a crucial subject due to in conventional bulk stainless steels both phases display very different mechanical, electrical, thermal and magnetic properties. Some authors have admitted metastable condensation of ferrite from the plasma, while others have suggested a 'quenching like' mechanism for formation of ferrite from austenite. Stability of austenite in bulk SS with chemical composition close to the 316 SS (austenitic SSs) has been the starting point for assuming metastability of ferrite in

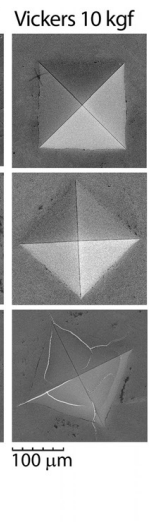

Figure 6. Surface appearance of selected samples studied by Knoop and Vickers indentation as observed in the SEM facility. Secondary electrons. Surfaces not chemically etched. 

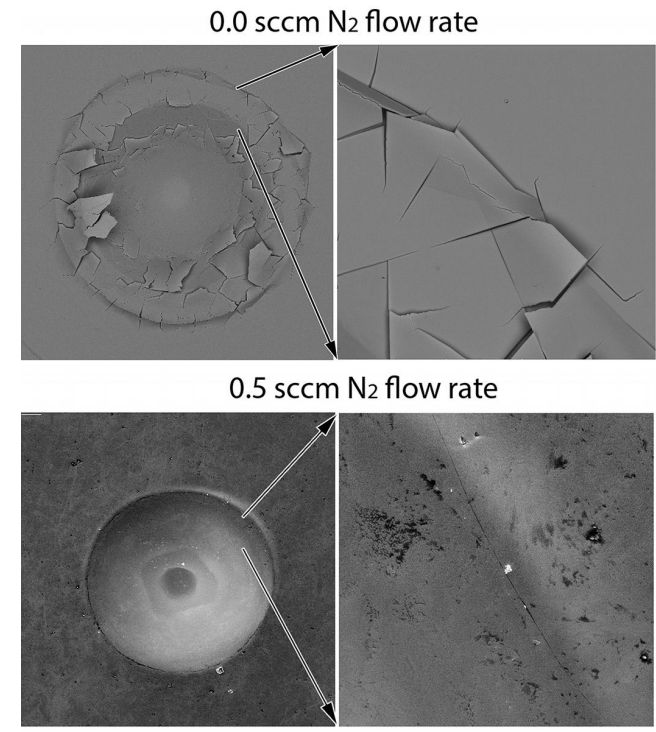

$1.8 \mathrm{sccm} \mathrm{N} 2$ flow rate
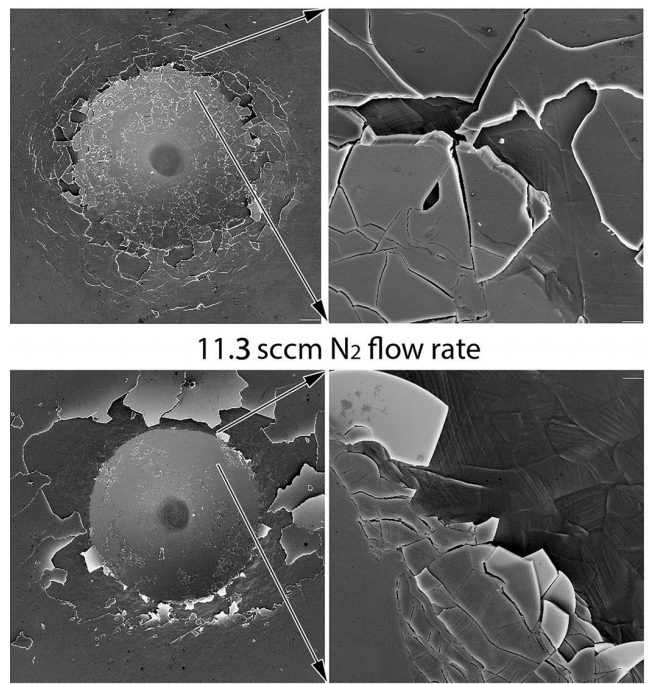

لسلسبا

$0.5 \mathrm{~mm}$

\section{$\mathrm{N}_{2}$ flow rate}

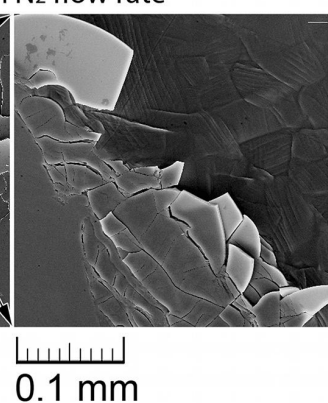

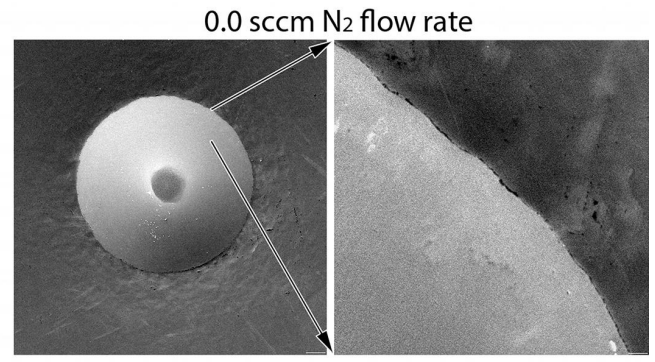

$0.5 \mathrm{sccm} \mathrm{N} \mathrm{N}_{2}$ flow rate

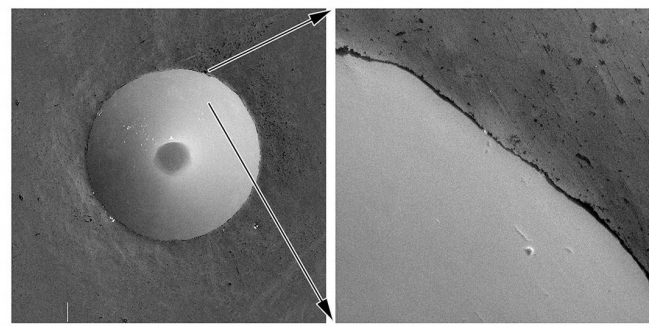

$1.8 \mathrm{sccm} \mathrm{N} \mathrm{N}_{2}$ flow rate

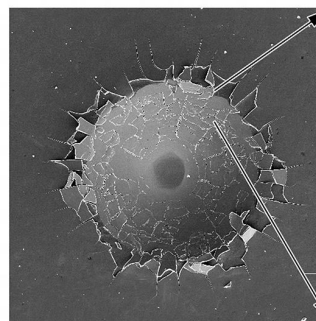

لسلسسا

$0.5 \mathrm{~mm}$

(b) $573 \mathrm{~K}$ external substrate heating, $-250 \mathrm{~V}$ bias voltage, $10.3 \mathrm{Wcm}^{-2}$ power density

\section{(a) Non-external substrate heating, non-bias voltage, $7 \mathrm{Wcm}^{-2}$ power density}

Figure 7. Effects of sputtering conditions on the surface appearance of samples tested under Rockwell indentation. SEM micrographs. Secondary electrons. Surfaces not chemically etched.

Table 2. Effects of sputtering conditions on critical loads for inducing formation of cracks under Knoop and Vickers indentations, and HF performance index ${ }^{f}$ for samples tested under Rockwell indentations.

\begin{tabular}{|c|c|c|c|c|}
\hline Sputtering conditions & $\mathrm{N}_{2}$ flow rate, $\mathrm{sccm}$ & $\begin{array}{l}\text { Critical load Knoop } \\
\text { tests kgf }\end{array}$ & $\begin{array}{c}\text { Critical load Vickers } \\
\text { tests kgf }\end{array}$ & $\begin{array}{c}\text { HF performance } \\
\text { index Rockwell tests } \\
\text { dimensionless }\end{array}$ \\
\hline \multirow{4}{*}{$\begin{array}{l}\text { Non-substrate heating, non- } \\
\text { bias, } 7 \mathrm{Wcm}^{-2}\end{array}$} & 0 & No cracking* & 3.0 & 2 \\
\hline & $0.53^{ \pm 0.03}$ & No cracking* & No cracking\& & 1 \\
\hline & $1.82^{ \pm 0.04}$ & 1.0 & 0.05 & 4 \\
\hline & $11.3^{ \pm 0.05}$ & 0.025 & 0.025 & 6 \\
\hline \multirow{3}{*}{$\begin{array}{l}573 \mathrm{~K} \text { substrate heating, } \\
-250 \mathrm{~V} \text { bias, } 10.3 \mathrm{Wcm}^{-2}\end{array}$} & 0 & No cracking* & No cracking ${ }^{\&}$ & 1 \\
\hline & $0.53^{ \pm 0.03}$ & No cracking* & No cracking ${ }^{\&}$ & 1 \\
\hline & $1.82^{ \pm 0.04}$ & No cracking* & 10.0 & 3 \\
\hline
\end{tabular}

* No formation of cracks was observed for indentation loads up to $2.0 \mathrm{kgf.}{ }^{\&}$ No formation of cracks was observed for indentation loads up to $10.0 \mathrm{kgf.}{ }^{\mathrm{E}}$ HF performance index was defined in accordance with Vidakis et al. ${ }^{30}$. 
nitrogen-lean sputtered films. However, the stability hierarchy between ferrite and austenite in 316-like SSs was recently studied, taking the lattice Gibbs free energy as a reference ${ }^{42}$. As an example, we mention that in reference ${ }^{42}$ it is reported that for a stainless steel alloyed with $18 \mathrm{wt}-\% \mathrm{Cr}$ and 9 wt- $\% \mathrm{Ni}$, Gibbs free energy steadily decreases from around $-2.8 \times 10^{4} \mathrm{Jmol}^{-1}$ at $750 \mathrm{~K}$ up to around $-4.3 \times 10^{4} \mathrm{Jmol}^{-1}$ at $950 \mathrm{~K}$, where at $750 \mathrm{~K}$ Gibbs free energy of ferrite is around $1 \%$ lower than that of austenite, while at $950 \mathrm{~K}$ Gibbs free energy of austenite is around $0.5 \%$ lower than that of ferrite. It was observed (based solely on chemical composition and lattice stability) at low thermal energy ferrite was associated to lower values of Gibbs free energy than austenite. Thus, we propose that ferrite observed in nitrogen-lean films which were grown with no substrate heating is more stable than the austenite. However, this can be pointed out that plasma discharge composition, plasma temperature and any other physical parameter related to energy of species on the plasma most probably can affect phase stability hierarchy (ferrite vs austenite) in the condensation and crystallization process of atomic species in the film. We suggest that an increasing of ion energy (via changes in plasma character) will induce stabilization of austenite against ferrite.

In bulk conventional SSs ( similar to the $316 \mathrm{SS}$ ), formation of austenite takes place at high temperature (casting, welding, heat treatment, etc), and transformation to the more stable ferrite is subsequently hindered by kinetic constraints. As a matter of fact, those bulk steels undergo martensitic transformation when they are cooled to cryogenic temperatures or they are intensely cold-worked.

Through magnetron-sputtering, adherent SS films with moderate susceptibility to crack formation in indentation tests can be deposited onto ASS substrates. The hardening effect of the surface-deposition treatment allows the maintenance of high hardness levels for indentation depths as high as $0.2-0.25$ of film thickness. However, susceptibility to indentation-induced cracking can be seriously hampered if deposition conditions are not carefully selected.

The critical indentation depth for the transition between intrinsic film hardness to film-substrate composite hardness was almost doubled (i.e., around 0.2 to 0.25 film thickness) that typically expected for hard films onto compliant substrates (i.e. around 0.07 to 0.1 film thickness). The high dependence observed for such critical indentation depth with the actual film structure is in accordance with the kinematic analysis of surface hardness for coated systems presented by Fernandes et al. ${ }^{43}$.

We attribute the high value of critical indentation for the onset of substrate-induced through-thickness softening to: (i) the close elastic compliance of both film and substrate (e.g., reference Zhou and Prorok ${ }^{44}$ ); and (ii) nitrogen-induced increase of through-thickness hardness at the region near the film-substrate interface.

Plasma discharge composition and formation of $\mathrm{N}_{2}^{+}$ions in the discharge most probably affect the critical indentation for the onset of substrate-induced through-thickness softening. In this contribution not plasma characterization was carried out. It is probably that formation of $\mathrm{N}_{2}^{+}$ions in the discharge affects film's growth mode, and thus the distribution of residual stresses, significantly affecting the film's load bearing ability.

A nitrogen-driven susceptibility to indentation-induced cracking was observed in this experiment. Using SEM examination of Knoop and Vickers imprints as a basis, it can be suggested that damage process in the indentation tests was mainly controlled by film deformation (both fragile and ductile deformation mechanisms were frequently observed), while the film to substrate delamination was a significant failure mechanism only when the previous film deformation was intense. In particular, in samples highly alloyed with nitrogen, early crack propagation can be seen near the indentation diagonals in Vickers tests. Thus, it can be suggested that the impaired susceptibility to crack formation detected in that sample alloyed with either 11.5, 22.0 or $47.0 \mathrm{~N}$ at- $\%$ is a straightforward consequence of nitrogen-induced ductility droop. Further tension-test analysis (out of the scope of this contribution) is required to establish the actual relationship between the film nitrogen content and film's ductility, as well as for assessing the fundamentals of the observed nitrogen-induced ductility droop.

Decreased capacity to bear contact loads without inducing fragile cracking which was exhibited by $\mathrm{N}$-lean samples in set-A, with regard to similar samples in set-B, can be attributed to changes in film structure induced by reduced adatom mobility in samples in the set-A. However, it is worth nothing that no evidence of such changes was observed either in the XRD analyses or by means of depth-sensing indentation analysis. Detailed information on the effect of adatom energy on film structure has been published by Thornton ${ }^{35}$. Structures grown at lower adatom energies are less dense and present a more profuse concentration of voids between grains ${ }^{35}$.

Differences (if any) in the resistance to crack formation in indentation regarding samples in set-A and set-B obtained with $0.53 \mathrm{sccm} \mathrm{N}$ flow rate were not detected. We suggest that the intrinsic ductile character of austenitic structures and the almost absent nitrogen-induced ductility droop in those samples (4.0 and $6.0 \mathrm{~N}$ at- $\%$ ) lead to ductile deformation when the samples are indented (even in macroindentation tests), being not possible to categorize the actual susceptibility to indentation-induced crack formation in those two sets of samples.

Samples obtained under $0.0 \mathrm{sccm}$ and $0.53 \mathrm{sccm} \mathrm{N} \mathrm{N}_{2}$ flow rate exhibited almost the same hardness, despite the fact that the latter were alloyed with nitrogen (4 and $6 \mathrm{~N}$ at- $\%$ ). Such seeming nitrogen-insensitive hardness is due to the change of ferrite to austenite, when samples N-lean and $\mathrm{N}$-alloyed are compared. Austenitic steel structures exhibit compact dislocation sleep systems, as a result of which, they are rendered intrinsically softer than comparable ferritic steel structures. Nitrogen hardening of austenite obtained under $0.53 \mathrm{sccm} \mathrm{N}_{2}$ flow rate most probably leads to harder structures than equivalent N-lean austenitic structures (not obtained in this contribution).

Hardness and elastic moduli reported in this contribution are significantly lower than similar data reported by Dearnley and Aldrich-Smith ${ }^{20}$ for comparable SS films. On the other hand, the hardness of the S-phase reported in this contribution (between 12.4 and $15.2 \mathrm{GPa}$ ) is close to hardness reported elsewhere for the S-phase obtained by 
plasma nitriding of the $316 \mathrm{~L} \mathrm{ASS}$, which typically ranges between 7 and $16 \mathrm{GPa}^{45-48}$.

We attribute the disagreement between hardness data in this contribution and those reported by Dearnley and Aldrich-Smith ${ }^{20}$ to differences in the calibration setup. Data on mechanical properties assessed from depth-sensing tests are appraised using an indirect approach ${ }^{29}$, which is highly susceptible to minor changes in the experimental setup. In particular, it is hard to adequately account for the indentation size effect in the range of low indentation depths.

Elastic moduli of ferritic films obtained (203 and $206 \mathrm{GPa}$ ) are in close agreement with the accepted value (200-220 GPa) of the tension elastic modulus for wrought ferritic SSs. Elastic moduli reported for (i) bare substrate, (ii) films mildly alloyed with nitrogen, and (iii) S-phase films (188 to $218 \mathrm{GPa}$ ) are in close agreement with the accepted value (193 GPa) of the tension elastic modulus for wrought UNS S31603 SS. No exist data reported for the elastic modulus of the $\mathrm{MN}$ nitride obtained in this contribution, which was identified previously by Kappaganthu and $\mathrm{Sun}^{33}$. The fundamentals for the decreased hardness and elastic modulus (8.1 and $139 \mathrm{GPa}$, respectively) of the MN nitride are unknown. Similar FCC CrN nitride typically exhibits 15 to $25 \mathrm{GPa}$ hardness ${ }^{49}$.

\section{Conclusions}

Regarding the effects of varying the nitrogen flow rate on indentation-assessed mechanical properties of SS films sputtered onto SS substrates of the same specification (UNS S3603) the following conclusions can be stated:

1. Nitrogen hardening in FCC crystal structure was observed (maximum hardness 15.2 GPa), provided that the MN nitride is not formed (hardness 8.1 GPa).

2. Elastic moduli gently varied between 193 and 218 $\mathrm{GPa}$ among the diverse samples with either ferrite or S-phase structures, excepting the set of samples with MN nitride, which displayed $139 \mathrm{GPa}$ elastic modulus.

3. Excessive nitrogen alloying (higher than around 11.5 $\mathrm{N}$ at-\%) impairs the resistance to crack formation in indentation tests, which leads to extensive film fragile damage under both micro- and macro-indentation. This increased susceptibility to indentation-induced cracking was readily addressed to a nitrogen-induced ductility droop.

\section{Acknowledgments}

The authors knowledge the financial and structural support provided by Santa Catarina State University (UDESC), Brazil, National University of Colombia (UNAL), Colombia, and the Thin Films, Surface Science, and Plasma Lab Facility (LPFS), Brazil. Thanks for the financial support Project FAPESC PAP/UDESC - CNPq-04/2018 - Grant term 2019TR781.

\section{References}

1. Lo KH, Shek CH, Lai JKL. Recent developments in stainless steels. Mater Sci Eng R-Rep. 2009;65(4-6):39-104. http:// dx.doi.org/10.1016/j.mser.2009.03.001.
2. Li T, Liu L, Zhang B, Li Y, Wang FH. Crevice corrosion behavior of nanocrystalline stainless steel fabricated by magnetron sputtering in chloride containing solution. J Electrochem Soc. 2015;162(7):C354-61. http://dx.doi.org/10.1149/2.0791507jes.

3. Li T, Liu L, Zhang B, Li Y, Wang FH. An investigation on the continuous and uniform thin membrane passive film formed on sputtered nanocrystalline stainless steel. Corros Sci. 2016;104:7183. http://dx.doi.org/10.1016/j.corsci.2015.11.031.

4. Zhang X, Misra A, Schulze RK, Wetteland CJ, Wang H, Nastasi M. Critical factors that determine face-centered cubic to bodycentered cubic phase transformation in sputter-deposited austenitic stainless steel films. J Mater Res. 2004;19(6):1696-702. http:// dx.doi.org/10.1557/JMR.2004.0215.

5. Eymery JP, Merakeb N, Goudeau P, Fnidiki A, Bouzabata B. A Mössbauer comparative study of the local environment in metastable 304 stainless steel films depending on the preparation mode. J Magn Magn Mater. 2003;256(1-3):227-36. http://dx.doi. org/10.1016/S0304-8853(02)00487-0.

6. Varasteh M, Parvin K, Boekema C, Porush K. Mossbauer spectroscopy and magnetic properties of copper-304 stainless steel multilayer films. J Appl Phys. 2000;87(9):6842-4. http:// dx.doi.org/10.1063/1.372860.

7. Zhang X, Misra A, Wang H, Lima AL, Hundley MF, Hoagland RG. Effects of deposition parameters on residual stresses, hardness and electrical resistivity of nanoscale twinned 330 stainless steel thin films. J Appl Phys. 2005;97(9):094302. http://dx.doi.org/10.1063/1.1883724.

8. Carretero E, Alonso R, Pelayo C. Optical and electrical properties of stainless steel oxynitride thin films deposited in an in-line sputtering system. Appl Surf Sci. 2016;379:249-58. http:// dx.doi.org/10.1016/j.apsusc.2016.04.052.

9. Pan C, Liu L, Li Y, Wang FH. Pitting corrosion of 304ss nanocrystalline thin film. Corros Sci. 2013;73:32-43. http:// dx.doi.org/10.1016/j.corsci.2013.03.022.

10. Figueiredo Pina CG, Dahm KL, Fisher J, Dearnley PA. The damage tolerance of S-phase coated biomedical grade stainless steel. Wear. 2007;263(7-12):1081-6. http://dx.doi.org/10.1016/j. wear.2006.10.025

11. Juang RC, Yeh YC, Chang BH, Chen WC, Chung TW. Preparation of solar selective absorbing coatings by magnetron sputtering from a single stainless steel target. Thin Solid Films. 2010;518(19):5501-4. http://dx.doi.org/10.1016/j.tsf.2010.04.025.

12. Ma X, Wei Q, Liu N, Wang X. Preparation and optical properties of $\mathrm{Cu} / \mathrm{SS}-\mathrm{TiON}(\mathrm{HMVF}) / \mathrm{SS}-\mathrm{TiON}(\mathrm{LMVF}) / \mathrm{A} 12 \mathrm{O} 3$ novel solar selective absorbing film. Mater Sci Eng Powder Metall. 2017;22:86-93.

13. Gao XH, Guo ZM, Geng QF, Ma PJ, Liu G. Microstructure and optical properties of $\mathrm{SS} / \mathrm{Mo} / \mathrm{A} 12 \mathrm{O} 3$ spectrally selective solar absorber coating. J Mater Eng Perform. 2017;26(1):161-7. http://dx.doi.org/10.1007/s11665-016-2445-1

14. Alresheedi FI, Krzanowski JE. Structure and morphology of stainless steel coatings sputter-deposited in a nitrogen/argon atmosphere. Surf Coat Tech. 2017;314:105-12. http://dx.doi. org/10.1016/j.surfcoat.2016.09.063.

15. Suszko T, Gulbiński W, Morgiel J, Greczynski G, Dobruchowska E, Dłużewski P, et al. Amorphous FeCrNi/a-C:H coatings with self-organized nanotubular structure. Scr Mater. 2017;136:24-8. http://dx.doi.org/10.1016/j.scriptamat.2017.03.040.

16. Merakeb N, Messai A, Ayesh AI. Investigation of phase transformation for ferrite-austenite structure in stainless steel thin films. Thin Solid Films. 2016;606:120-6. http://dx.doi. org/10.1016/j.tsf.2016.03.038.

17. Baranowska J, Fryska S, Suszko T. The influence of temperature and nitrogen pressure on S-phase coatings deposition by reactive magnetron sputtering. Vacuum. 2013;90:160-4. http://dx.doi. org/10.1016/j.vacuum.2012.03.054.

18. Seelam UMR, Suryanarayana C. Metallography of sputterdeposited SS304+Al coatings. Metallography, Microstructure, 
and Analysis. 2013;2(5):287-98. http://dx.doi.org/10.1007/ s13632-013-0087-3.

19. Aldrich-Smith G, Teer DG, Dearnley PA. Corrosion-wear response of sputtered $\mathrm{CrN}$ and S-phase coated austenitic stainless steel. Surf Coat Tech. 1999;116-119:1161-5. http:// dx.doi.org/10.1016/S0257-8972(99)00222-4.

20. Dearnley PA, Aldrich-Smith G. Corrosion-wear mechanisms of hard coated austenitic 316L stainless steels. Wear. 2004;256(5):4919. http://dx.doi.org/10.1016/S0043-1648(03)00559-3.

21. Sun Y, Kappaganthu SR. Effect of nitrogen doping on sliding wear behaviour of stainless steel coatings. Tribol Lett. 2004;17(4):84550. http://dx.doi.org/10.1007/s11249-004-8092-y.

22. Zhang X, Misra A, Wang H, Nastasi M, Embury JD, Mitchell TE, et al. Nanoscale-twinning-induced strengthening in austenitic stainless steel thin films. Appl Phys Lett. 2004;84(7):1096-8. http://dx.doi.org/10.1063/1.1647690.

23. Bourjot A, Foos M, Frantz C. Basic properties of sputtered 310 stainless steel-nitrogen coatings. Surf Coat Tech. 1990;4344:533-42. http://dx.doi.org/10.1016/0257-8972(90)90104-K.

24. Von Stebut J, Darbeïda A, Saker A, Billard A, Rezakhanlou R. Optimization of the contact mechanical strength of magnetronsputtered nitrogen-doped AISI 316L physically vapour deposited coatings. Surf Coat Tech. 1993;57(1):31-42. http://dx.doi. org/10.1016/0257-8972(93)90333-J.

25. Rezakhanlou R, Billard A, Foos M, Frantz C, Von Stebut J. Influence of the intrinsic coating properties on the contact mechanical strength of perfectly adhering carbon-doped AISI 310 PVD films. J Surf. Coat. Tech. 1990;43-44:907-19. http:// dx.doi.org/10.1016/0257-8972(90)90031-7.

26. Talea M, Boubeker B, Cleymand F, Coupeau C, Grilhe J, Goudeau P. Atomic force microscopy observations of debonding in $304 \mathrm{~L}$ stainless steel thin films. Mater Lett. 1999;41(4):181-5. http:// dx.doi.org/10.1016/S0167-577X(99)00127-5.

27. Colin J, Cleymand F, Coupeau C, Grilhé J. Worm-like delamination patterns of thin stainless steel films on polycarbonate substrates. Philos Mag A Phys Condens Matter Struct Defects Mech Prop. 2000;80(11):2559-65. http://dx.doi. org/10.1080/01418610008216492.

28. Eymery JP, Boubeker B. Adhesion and debonding of bec 304 L steel films. Mater Lett. 1994;19(3-4):137-42. http://dx.doi. org/10.1016/0167-577X(94)90058-2.

29. Oliver WC, Pharr GM. An improved technique for determining hardness and elastic modulus using load and displacement sensing indentation experiments. J Mater Res. 1992;7(6):156483. http://dx.doi.org/10.1557/JMR.1992.1564.

30. Vidakis N, Antoniadis A, Bilalis N. The VDI 3198 indentation test evaluation of a reliable qualitative control for layered compounds. J Mater Process Technol. 2003;143-144:481-5. http://dx.doi.org/10.1016/S0924-0136(03)00300-5.

31. Schneider JM, Rebholz C, Voevodin AA, Leyland A, Matthews A. Deposition and characterization of nitrogen containing stainless steel coatings prepared by reactive magnetron sputtering. Vacuum. 1996;47(9):1077-80. http://dx.doi.org/10.1016/0042207X(96)00143-1.

32. Kappaganthu SR, Sun Y. Influence of sputter deposition conditions on phase evolution in nitrogen-doped stainless steel films. Surf Coat Tech. 2005;198(1-3):59-63. http://dx.doi.org/10.1016/j. surfcoat.2004.10.047.

33. Kappaganthu SR, Sun Y. Formation of an MN-type cubic nitride phase in reactively sputtered stainless steel-nitrogen films. J Cryst Growth. 2004;267(1-2):385-93. http://dx.doi. org/10.1016/j.jcrysgro.2004.03.066.

34. Terwagne G, Hody H, Colaux J. Structural and quantitative analysis of stainless steel coatings deposited by DC-magnetron sputtering in a reactive atmosphere. Surf Coat Tech. 2003;174175:383-8. http://dx.doi.org/10.1016/S0257-8972(03)00594-2.

35. Thornton JA. High rate thick film growth. Annu Rev Mater Sci. 1977;7:239-60.

36. Kersten H, Deutsch H, Steffen H, Kroesen GM, Hippler R. The energy balance at substrate surfaces during plasma processing. Vacuum. 2001;63(3):385-431. http://dx.doi.org/10.1016/S0042207X(01)00350-5.

37. Somekh RE. The thermalization of energetic atoms during the sputtering process. J Vac Sci Technol. 1984;2(3):1285-91. http://dx.doi.org/10.1116/1.572396.

38. Sakharova NA, Oliveira MC, Antunes JM, Fernandes JV. On the determination of the film hardness in hard film/substrate composites using depth-sensing indentation. Ceram Int. 2013;39(6):625163. http://dx.doi.org/10.1016/j.ceramint.2013.01.046.

39. Puchi-Cabrera ES, Staia MH, Iost A. Modeling the composite hardness of multilayer coated systems. Thin Solid Films. 2015;578:53-62. http://dx.doi.org/10.1016/j.tsf.2015.01.070.

40. Liu H, Xu Q, Zhang X, Wang C, Tang B. Residual stress analysis of TiN film fabricated by plasma immersion ion implantation and deposition process. Nucl Instrum Methods Phys Res Sect B. 2013;297:1-6. http://dx.doi.org/10.1016/j.nimb.2012.12.015.

41. Kappaganthu SR, Sun Y. Studies of structure and morphology of sputter-deposited stainless steel-nitrogen films. Appl Phys, A Mater Sci Process. 2005;81(4):737-44. http://dx.doi.org/10.1007/ s00339-004-3144-6.

42. Garzón CM, Recco A A C. Numerical simulation on phase stability between austenite and ferrite in steel films sputterdeposited from austenitic stainless steel targets. Surf Coat Tech. 2018;353:84-92. http://dx.doi.org/10.1016/j.surfcoat.2018.08.068.

43. Fernandes JV, Menezes LF, Trindade AC. The coated surface hardness: a kinematic model. Thin Solid Films. 1998;335(12):153-9. http://dx.doi.org/10.1016/S0040-6090(98)00864-5.

44. Zhou B, Prorok C. A discontinuous elastic interface transfer model of thin film nanoindentation. Exp Mech. 2010;50(6):793801. http://dx.doi.org/10.1007/s11340-009-9309-7.

45. Li Y, Wang Z, Wang L. Surface properties of nitrided layer on AISI 316L austenitic stainless steel produced by high temperature plasma nitriding in short time. Appl Surf Sci. 2014;298:243-50. http://dx.doi.org/10.1016/j.apsusc.2014.01.177.

46. Samanta A, Chakraborty H, Bhattacharya M, Ghosh J, Sreemany $\mathrm{M}$, Bysakh S, et al. Nanotribological response of a plasma nitrided bio-steel. J Mech Behav Biomed Mater. 2017;65:584 99. http://dx.doi.org/10.1016/j.jmbbm.2016.09.017.

47. Asgari M, Barnoush A, Johnsen R, Hoel R. Microstructural characterization of pulsed plasma nitrided 316L stainless steel. Mater Sci Eng A. 2011;529:425-34. http://dx.doi.org/10.1016/j. msea.2011.09.055.

48. Singh V, Marchev K, Cooper CV, Meletis EI. Intensified plasma-assisted nitriding of AISI 316L stainless steel. Surf Coat Tech. 2002;160(2-3):249-58. http://dx.doi.org/10.1016/ S0257-8972(02)00403-6.

49. Lin J, Moore JJ, Sproul WD, Mishra B, Wu Z, Wang J. The structure and properties of chromium nitride coatings deposited using dc, pulsed dc and modulated pulse power magnetron sputtering. Surf Coat Tech. 2010;204(14):2230-9. http://dx.doi. org/10.1016/j.surfcoat.2009.12.013. 